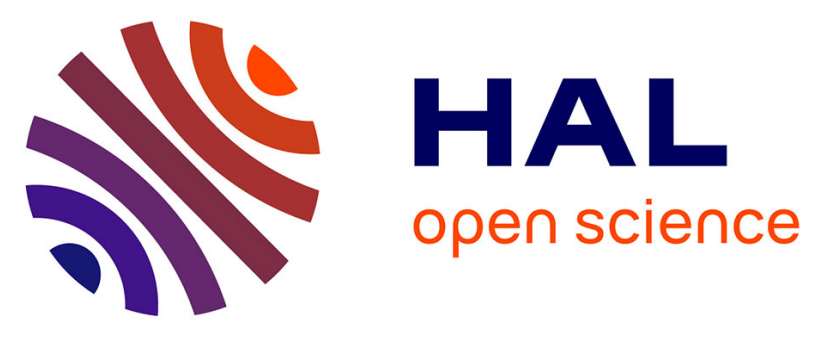

\title{
Computational Modeling of the Main Signaling Pathways Involved in Mast Cell Activation
}

Anna Niarakis, Yacine Bounab, Luca Grieco, Romain Roncagalli, Anne-Marie Hesse, Jérôme Garin, Bernard Malissen, Marc Daëron, Denis Thieffry

\section{- To cite this version:}

Anna Niarakis, Yacine Bounab, Luca Grieco, Romain Roncagalli, Anne-Marie Hesse, et al.. Computational Modeling of the Main Signaling Pathways Involved in Mast Cell Activation. Marc Daëron; Falk Nimmerjahn. Fc Receptors, 382, Springer, pp.69-93, 2014, Current Topics in Microbiology and Immunology, 978-3-319-07911-0. 10.1007/978-3-319-07911-0_4 . hal-02086273

\section{HAL Id: hal-02086273 https://hal.science/hal-02086273}

Submitted on 28 Feb 2022

HAL is a multi-disciplinary open access archive for the deposit and dissemination of scientific research documents, whether they are published or not. The documents may come from teaching and research institutions in France or abroad, or from public or private research centers.
L'archive ouverte pluridisciplinaire HAL, est destinée au dépôt et à la diffusion de documents scientifiques de niveau recherche, publiés ou non, émanant des établissements d'enseignement et de recherche français ou étrangers, des laboratoires publics ou privés.

$$
\text { Copyright }
$$




\title{
Computational modeling of the main signaling pathways involved in mast cell activation
}

\author{
Anna Niarakis 1, 2, 3, *, Yacine Bounab ${ }^{4,5}$, Luca Grieco6, 7, Roman Roncagalli ${ }^{8,9,}$, ${ }^{6}$, Anne-Marie

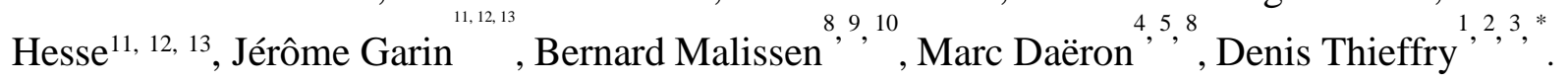

\begin{abstract}
A global and rigorous understanding of the signaling pathways and cross-regulatory processes involved in mast cell activation requires the integration of published information with novel functional datasets into a comprehensive computational model. Based on an exhaustive curation of the existing literature and using the software CellDesigner, we have built and annotated a comprehensive molecular map for the FceRI signaling network. This map can be used to visualize and interpret high-throughput expression data. Furthermore, leaning on this map and using the logical modeling software GINsim, we have derived a qualitative dynamical model, which recapitulates the most salient features of mast cell activation. The resulting logical model can be used to explore the dynamical properties of the system and its responses to different stimuli, in normal or mutant conditions.
\end{abstract}

1 Ecole Normale Supérieure, Institut de Biologie de l'ENS (IBENS), Paris, France.

2 INSERM, U1024, Paris, France.

3 CNRS, UMR 8197, Paris, France.

* Corresponding authors Institut Pasteur, Département d'Immunologie, Unité d'Allergologie Moléculaire et Cellulaire, Paris, France.

5 INSERM, UMS20, Paris, France.

6 Institut Curie, Paris, France.

7 INSERM, U900, Paris, France.

8 Centre d'Immunologie de Marseille-Luminy (CIML), Université Aix Marseille, Marseille, France.

9 INSERM, U1104, Marseille, France.

10 CNRS, UMR7280, Marseille, France.

11 CEA, IRTSV, Laboratoire de Biologie à Grande Echelle, Grenoble, France.

12 INSERM, U1038, Grenoble, France.

13 Université de Grenoble Alpes, iRTSV, Laboratoire de Biologie à Grande Echelle, Grenoble, France. 


\section{Contents}

\section{Introduction}

2. A comprehensive map of FceRI signaling during mast cell activation

3. Signaling events covered in the CellDesigner molecular map

3.1. FceRI mediated signaling

3.2. FceRI aggregation and Lyn/Syk/Fyn-dependent events

3.3. FcrRIIB-mediated signaling

3.4 LAT1-dependent protein complex formation

3.5. LAT2-dependent protein complex formation

4. Access to the mast cell activation map

4.1. CellDesigner file

4.2. Import into Cytoscape

4.3. REACTOME database

4.4. NaviCell

5. Community driven update of mast cell activation map

6. Visualization of proteomic data on the CellDesigner map

7. Modularization and decomposition of the molecular map using BiNoM

8. Logical modeling of mast cell activation network

9. Coherence of the logical model behavior with published data

10. Outlook

Acknowledgements

References 


\section{Introduction}

Mast cell activation is a pivotal event in the initiation of inflammatory reactions associated with allergic disorders. It is triggered by the aggregation of high affinity IgE receptors (FceRI) on the mast cell surface, which is in turn induced by the binding of a multivalent allergen to FceRI-bound IgE antibodies. Mast cell activation is a complex process relying on multiple layers of tightly controlled intracellular signaling molecules, which form an intricate network. Mast cells are crucially important for innate immunity and further play an effective role in the amplification of adaptive immunity. Mast cells are key players in biological responses, both in harmless and harmful situations, and it has been long known that they play a central role in type I hypersensitivity reactions and allergic disorders.

A global and rigorous understanding of the signaling pathways and cross-regulatory processes involved in mast cell activation ultimately requires the integration of published information with novel functional genomic datasets, in particular proteomic data, into a comprehensive computational model. In this respect, we engaged into an integrative approach involving two main steps: (i) the construction of a comprehensive and extensively annotated molecular map: (ii) the derivation of a qualitative dynamical model.

The construction of detailed molecular pathway maps is becoming an important component of system biology as attested by the release of various maps dealing, for example, with mTOR signaling (Caron et al., 2010), EGFR (Oda et al., 2005), RB/E2F (Calzone et al., 2008), and MAPKs (Grieco et al., 2013). These maps are integrated in dedicated databases, such as KEGG (Kanehisa and Goto, 2000), Transpath (Krull et al., 2006), Reactome (Joshi-Tope et al., 2005), and the Atlas of Cancer Signaling Networks (http://acsn.curie.fr).

The use of graphical representations of complex networks and pathways is spreading as a consequence of the rising of Systems Biology and Synthetic Biology fields. The presence of a consistent, standardized way of representation and interpretation of molecular maps is of outmost importance to enable exchange of information in a quick, unambiguous and systematic way. A consistent notation also helps improving biological curation (Hucka et al., 2003). An important effort towards this direction has been made recently with the Systems Biology Graphical Notation (SBGN) (Le Novere et al., 2005; Klipp et al., 2007).

To cope with large cellular networks for which precise kinetic data are lacking, logical modeling is increasingly used to derive global qualitative insights about network dynamics (for recent reviews, see Glass and Siegelmann, 2010; Bérenguier et al., 2013). Recent applications to mammalian networks include logical models for T-helper cell differentiation (Mendoza, 2006; Naldi et al., 2011), T cell receptor signaling (Saez-Rodriguez et al., 2007), Erb-b receptor signaling (Sahin et al., 2009; Samaga et al., 2009; Helikar et al., 2013), as well as for the main MAPK pathways, including feedbacks and cross-talks (Grieco et al., 2013). Finally, several kinetic models dealing with subparts of the mast cell FceRI signaling pathway have already been published, especially focusing on the early signaling events mediated by FceRI (Goldstein et al., 2002; Nag et al., 2010).

If not absolutely required, a detailed molecular map is certainly an excellent basis to build a dynamical model. Perhaps less intuitively, the derivation of a dynamical model forces the biologist to scrutinize the mapped pathways with specific emphases, often provoking the reconsideration of some aspects of the map. Finally, model simulations often result in inconsistencies, thereby fostering the need for further refinements.

In short, the computational modeling of complex signaling networks thus involves various iterations of data curation, molecular mapping and dynamical modeling, until sufficient consistency is reached (see flowchart in Figure 1). 


\section{A comprehensive map of FecRI signaling during mast cell activation}

Molecular maps of several pathways associated with FceRI signaling events during mast cell activation can be found in public databases, with variable levels of detail and different representations (see Table I). These maps can take the form of simplified graphs focusing on selected components or events, while others are much more comprehensive, encompassing various related pathways. They also differ regarding the number of references, as well as updating frequency.

At this stage, however, we felt that existing maps still lack details to support the development of predictive models. Consequently, we engaged in the development of a novel, comprehensive molecular map of the signaling network underlying mast cell activation, based on an extensive analysis of relevant scientific papers and reviews, and taking into account existing pathways available in public databases (Figure 2). This map has been built using the software CellDesigner (versions 4.2 and 4.3; Funahashi et al., 2003).

The nodes (vertices) of this map represent proteins and their post-transcriptional variants, protein complexes, metabolites, or genes, while links (arcs) represent molecular reactions (complex formation or dissociation, post-transcriptional modification of proteins, etc.). All nodes and links are extensively annotated with textual information tracing experimental support, along with links to databases, e.g. to relevant scientific papers in PubMed, or to representative entries in genomic databases such as EntrezGene, UniProt or HUGO.

Our current mast cell activation signaling network includes information derived from over 200 peer-reviewed journal articles. We primarily focused on human data, but we incorporated information coming from studies in mice or rats whenever human data were lacking. Similarly, we primarily focused on mast cell-specific data, but we further took into account results of studies dealing with $\mathrm{B}$ and $\mathrm{T}$ lymphocytes to fill gaps in our current knowledge of mast cell signaling. Inference by homology (from different species or from different cell types) is systematically emphasized in component annotations.

The resulting map encompasses a total of 122 distinct chemical species (proteins, ion channels, ions, receptors, complexes, chemical entities/ compounds) and 73 reactions (arcs) taking place in five main compartments (cytoplasm, plasma membrane, Golgi apparatus, endoplasmic reticulum, nucleus). The reactions encompass 39 state transitions (including catalysis), 30 heterodimer association, 2 transports and 2 dissociations. Hereafter, we describe the main data integrated in our molecular map in more details (the CellDesigner map is available on request).

\section{Signaling events covered in the CellDesigner molecular map}

\subsection{FceRI mediated signaling}

The mast cell receptors FceRI belong to the Fc receptor family and can bind a variety antibodies (Ab). On mast cells, Fc receptors bind exclusively $\operatorname{IgE}$ or $\operatorname{IgG}$ ( $\mathrm{Fc} \gamma$ receptors). FceRI consist of three subunits: an IgE-binding alpha subunit, a signal-amplifying beta subunit, and a signalinitiating homodimeric gamma subunit (Kinet, 1999). The beta and gamma subunits contain one tyrosine activation motif (ITAM) each. The phosphorylation of ITAM canonical tyrosine residues initiates a cascades or intracellular events.

\subsection{FceRI aggregation and Lyn/Syk/Fyn-dependent events}

The Src protein tyrosine kinase Lyn is responsible for the phosphorylation of the ITAM motifs of FceRI. Like other Src family kinases, Lyn is anchored in the lipid rafts via its palmitoyl or 
myristoyl moieties. FceRI stimulation causes an accumulation of these protein tyrosine kinases (PTKs) in lipid raft domains (Kovárová et al., 2001). Moreover, the localization of Lyn in lipid rafts is necessary to sustain FceRI phosphorylation and to maintain an active Lyn kinase (Young et al., 2003). Following FceRI aggregation on the mast cell surface, Lyn phosphorylates the ITAMs of the beta and gamma chains. When phosphorylated, these motifs can recruit Syk (Spleen tyrosine kinase). Syk is then phosphorylated by Lyn and autophosphorylates.

Active Syk in turns phosphorylates the transmembrane adaptors LAT1 and LAT2, as well as several cytosolic proteins including Gab2, Clnk, SLP76, Shc and Btk (Simon et al., 2005).

Activated Lyn further phosphorylates Fyn, which is important for the activation of Btk and Gab2. Fyn is also needed for the activation of PI3K via Fyn-dependent phosphorylation of Gab2. PI3K is essential for the production of PIP3 (Kraft \& Kinet, 2007). PIP3 is the product of PI3K phosphorylation of phosphatidylinositol (4,5)-bisphosphate (PIP2). Residing on the membrane, this phospholipid causes various proteins with a PH domain to translocate to the plasma membrane and affects their activity accordingly. This includes Akt activation, which in turn activates downstream anabolic signaling pathways required for cell growth and survival.

Fyn activity is regulated by $\mathrm{Cbp} / \mathrm{PAG}$ adaptor. This adaptor recruits the negatively regulatory kinase Csk, which in turns phosphorylates Fyn and thereby inactivates it (Alvarez- Errico et al., 2009).

\subsection{FcyRIIB-mediated signaling}

The single-chain low-affinity IgG receptors Fc $\gamma$ RIIB are widely expressed by hematopoietic cells, including mast cells. They inhibit FceRI-dependent mast cell activation (Daëron et al., 1995a,b). When IgG-allergen immune complexes co-aggregate FceRI and Fc $\gamma$ RIIB, Lyn phosphorylates the ITAMs of FceRI and the ITIM (Immune receptor Tyrosine based Inhibitory Motif) of Fc $\gamma$ RIIB (Malbec et al., 1998). Phosphorylation of the Fc $\gamma$ RIIB ITIM results in the recruitment of SHIP1, which in turn recruits Dok1 and RasGAP. RasGAP inhibits SOS, thereby interrupting Ras activation, as well as subsequent transcriptional regulation and lipid mediator production. Constitutively bound to Shc in the cytoplasm, Grb2 is then further recruited (Jabril-Cuenod et al., 1996). Moreover, SHIP1 hydrolizes PIP3, resulting in a decrease of PLC $\gamma$, IP3 and $\mathrm{Ca}^{2+}$ fluxes. Fc $\gamma$ RIIB cooperate with FceRI for the activation of Ca2+ fluxes, as well as of MAPK pathway (Kraft \& Kinet, 2007).

SHIP1 is an important regulator of intracellular levels of PIP3. PtdIns(3,4,5)P3 is dephosphorylated by SHIP1 (SH2-containing inositol phosphatase) on the 5' position of the inositol ring, producing PI $(3,4) \mathrm{P} 2$, thereby down-regulating Akt activity.

\subsection{LAT1-dependent protein complex formation}

LAT1 is a transmembrane protein that is essential for the propagation of FceRI-mediated signaling. It acts as an adaptor molecule and enables the association of different proteins such as Grb2, Gads, SLP76, Btk, Vav1, PLC $\gamma$ (Saitoh et al., 2000). LAT1 undergoes lipid modification such as palmitoylation and acylation, which determines its cellular localization (Gilfillan \& Tkaczyk, 2006). Syk phosphorylates LAT1 shortly after antigen stimulation. Phosphorylated LAT1 plays the role of a signaling platform. It provides binding sites for the direct binding of Grb2, Gads and PLC $\gamma$ (Saitoh et al., 2000). Grb2/SOS complex recruits activated Shc. LAT1 binds SOS and Shc via Grb2. Gads recruits activated SLP76, which in turns recruits Btk and Vav, while Btk phosphorylates PLC $\gamma$.

Tyrosine-phosphorylated PLC $\gamma$ in the membrane hydrolyzes PIP2, forming the second messengers IP3 and 1,2-diacylglycerol, which lead to the release $\mathrm{Ca}^{2+}$ from internal stores and activate PKC, respectively. The binding of IP3 to specific receptors in the endoplasmic reticulum results in a 
depletion of $\mathrm{Ca}^{2+}$ stores, which activates store-operated $\mathrm{Ca}^{2+}$ entry (ICRAC) from the extracellular medium.

The importance of LAT1 in mast cell activation was demonstrated by experiments in LAT1deficient mice. LAT1 deficiency did not alter mast cell development and maturation, neither in vivo nor in vitro (Saitoh et al., 2000), but LAT1 deficient mice are resistant to IgE-mediated passive systemic anaphylaxis, while PLC $\gamma$ and SLP76 phosphorylation is markedly reduced (Alvarez-Errico et al., 2009).

\subsection{LAT2-dependent protein complex formation}

Similar to LAT1, LAT2 contains a palmitoylation site adjacent to the transmembrane domain involved in its localization to the lipid rafts. Its exact role in mast cells remains to be elucidated, but it has been shown to affect actin polymerization via Rac and Rho (Tumova et al., 2010). Like LAT1, it is able to recruit PLC $\gamma$, but in an indirect way, via Gab2, since LAT2 lacks the PLC $\gamma$ binding motif contained in LAT1 (Alvarez-Errico et al., 2009). LAT2 further affects degranulation through this indirect recruitment of PLC $\gamma$. However, in vivo experiments showed that the response of LAT2-deficient mice to systemic anaphylactic challenge is similar to that of wild type mice (Zhu et al., 2004). LAT2 may also regulate an inhibitory pathway for FceRI-mediated mast cell degranulation, at least in mouse bone marrow macrophages. LAT2 knock down in human mast cells and the RBL $2 \mathrm{H} 3$ rat mast cell line attenuates FceRI-mediated degranulation through reduction of the calcium signal. Subsequent studies suggested that this interaction may be occurring through SLP76. This maintenance/amplification pathway for antigen-mediated responses in mast cells may be the portal by which signaling pathways initiated by other mast cell receptors allow synergistic potentiation of FceRI-mediated degranulation and cytokine production (Gilfillan and Beaven, 2011). Upon FceRI aggregation, LAT2 is phosphorylated by Lyn, Syk and KIT on different tyrosines. Phosphorylated LAT2 likely contributes to the activation of mast cells by providing docking sites for the recruitment of critical signaling molecules into the lipid raft. LAT2 contains about ten tyrosines, five of which are principally phosphorylated by SYK, whereas others are phosphorylated by Lyn and KIT (Iwaki et al., 2008). After proper palmitoylation and phosphorylation, LAT2 recruits Grb2, which in turns recruits phosphorylated Gab2. The LAT2/Grb2/Gab2 complex recruits PI3K. In a different scenario, Grb2 binds to SOS, and the complex recruits activated Shc. The complex Shc/Grb2/SOS associates with LAT2.

\section{Access to the mast cell activation map}

\subsection{CellDesigner file}

As it was initially built using CellDesigner, the molecular map integrating all the aforementioned data is provided in the form of an $\mathrm{xml}$ file to be open with this software (xml file available on request). In this respect, the user must download, install and open this CellDesigner (http://www.celldesigner.org), and then import the xml file, which will enable navigation through the map with access to all annotations.

\subsection{Import into Cytoscape}

It is also possible to view the network through the popular software Cytoscape (http://cytoscape.org; Shannon et al., 2003) using the plugin BiNoM (http://apps.cytoscape.org/apps/binom). This requires to download and install the proper versions of Cytoscape 2.8.3 and BiNoM 2.3. Using these tools, the user can import the CellDesigner XML file and perform various kinds of analysis (examples of such analyses are provided below). 


\subsection{REACTOME database}

REACTOME is an open-source, open-access, manually-curated and peer-reviewed pathway database, which includes an intuitive interface along with various software tools to support the analysis of complex experimental and computational datasets.

An interface based on the Systems Biology Graphical Notation (SBGN), Pathway Browser, facilitates the visualization of Reactome data and supports zooming, scrolling and event highlighting. It further exploits web services (PSIQUIC) to overlay molecular interaction data from the Reactome Functional Interaction Network and external interaction databases, such as IntAct, ChEMBL, BioGRID and iRefIndex.

A first version of the mast cell signaling map has been integrated into REACTOME and can thus be browsed and queried directly from the corresponding website (http://www.reactome.org). In the course of the import of our map into REACTOME, all documented interactions were re-evaluated, the list of references enriched, and the resulting map was reviewed by experts before public release. Navigation into the REACTOME map can be done using a standard web browser, including access to all textual annotations, list of references and links to other databases, thereby avoiding the burden of downloading and installing a dedicated software such as CellDesigner or Cytoscape. Furthermore, all REACTOME maps can be easily exported into SBML, BioPAX and other formats to facilitate data exchange with other analysis and modeling tools.

\subsection{NaviCell}

Finally, the mast cell signaling map has been also integrated in the atlas developed by the Cancer Systems Biology team at Institute Curie (http://acsn.curie.fr). This atlas is published online using the software NaviCell, a web tool for exploring large maps of molecular interactions (https://navicell.curie.fr). NaviCell allows easy map navigation and access to the network components through the Google maps engine. Navigation, scrolling, zooming, pop-up bubbles have been adapted from Google maps. Semantic zooming enables users to explore the maps at different levels of detail. NaviCell further contains a web-based blog system (Wordpress) to collect feedbacks and facilitate exchange of knowledge between specialists and map managers (Kuperstein et al., 2013). The user can select species and reactions from a panel and get access to all annotations that were manually entered during map construction. Links to relevant PubMed entries are provided. Note that our original map includes protein nodes corresponding to more than one HUGO name (e.g ERK node denotes both MAPK1 and MAPK3 isoforms); in such cases we have selected unique representative identifiers.

\section{Community driven update of mast cell activation map}

The molecular map for mast cell signaling presented here is more detailed and comprehensive than the previous diagrams published in scientific journals or available in public databases. It should help biologists to better deal with the complexity of mast cell signaling network and help them to identify potential intervention points to block uncontrolled inflammation. Furthermore, as we shall see, this map can be used as a scaffold for systems biologists to derive dynamical models for mast cell activation. However, as novel data will accumulate, regular revisions of the map will be necessary. In this respect, wide availability of the map should foster feedbacks, comments and suggestions from the scientific community. 


\section{Visualization of proteomic data on the CellDesigner map}

The molecular map for mast cell signaling can be used as a template for the visualization of expression data, such as transcriptomic or proteomic data. For this purpose, CellDesigner provides a plugin (Mapping Array Mass) (version 4.0 and onward) that allows the import of an attribute file with the corresponding values. The color of the species is set according to the data value. An alternative way to color CellDesigner map components with expression data is provided by the Cytoscape plugin BiNoM (Zinovyev et al., 2008).

We illustrate this approach through the visualization of proteomic data on SLP-76 interactome published by Bounab et al. (2013) for activated BMMCs (Figure 3). Such coloration facilitates the interpretation of expression and interaction data in the context of the known network.

\section{Modularization and decomposition of the molecular map using BiNoM}

To get insights into the organization of the mast cell signaling network, we used the Cytoscape plugin BiNoM (Zinovyev et al., 2008). Among other features, BiNoM allows the decomposition of complex networks and the generation of several modular views. Such high level representations are fully based on the underlying detailed map and helps navigation through it. When necessary, the user can easily refer to the detailed mechanisms underlying a given module. A similar approach for modular pathway modeling has been implemented in the ProMoT system (Saez-Rodriguez et al., 2006).

Modularization consists in a semi-automatic procedure to delineate modules and ensures their coherence. Modules often represent detailed sequences of events involving either a particular protein or a particular complex. Compressing such sequences into modules enables a simplified and compact representation of complex pathways.

The decomposition of biological networks can be performed in different ways. First, we can separate unconnected network subparts, keeping only the connected components, i.e. decompose the network into (strongly) connected components. BiNoM further implements an algorithm enabling the generation of a pruned graph consisting in three main parts: the incoming flux part, from which all paths lead to the central core, the cyclic part that consists of strongly connected components, and the outgoing flux part, devoid of paths leading back to the central core. Figure 4 shows the pruned graph obtained from the application of this algorithm to our mast cell signaling network. Using another feature of BiNoM, the central core can be further decomposed into 12 simple cycles.

Still using BiNoM, the network can be decomposed into material components, each corresponding to one protein, either as a distinct chemical species or as part of a complex. As a protein can participate in different complexes, these subnetworks are usually largely overlapping. Another BiNoM function enables a clustering of these components based on common proteins or complexes and on an intersection percentage threshold specified by the user (Bonnet et al., 2013). Automatic decomposition of our molecular map resulted into 45 material components, which were then clustered for an intersection threshold set to $35 \%$. Manual curation led us to merge some of the 24 resulting components, ultimately defining the 12 modules shown in Figure 5.

Structural graph analysis gives us a first estimation of the complexity of the biological network and can also reveal important properties that are not obvious at first sight (e.g. non connected components, overlapping cycles). The modularization process enables a simplification of the network representation, allowing the user to supervise and check more easily the main events occurring in the network. Especially for very large networks containing hundreds of interactions, modularization greatly facilitates navigation.

Both modular views (pruned graph and material components graph) are useful for the development 
of a proper dynamical model (cf. following section), in particular to define the main variables and check that no important interaction is missed.

\section{Logical modeling of mast cell activation network}

Our mast cell signaling molecular map can be used as a reference to build a predictive dynamical model accounting for the most salient events following mast cell receptor activation. In the absence of detailed kinetic data, we decided to rely upon a sophisticated logical formalism implemented in the software GINsim (Chaouiya et al., 2012). In this framework, a regulatory network is modeled in terms of a regulatory graph, where nodes represent regulatory components (proteins, complexes, transcription factors, etc), whereas arcs represent interactions between these components. In addition, each regulatory component is associated with a logical variable denoting its qualitative concentration or level of activity. In most cases, Boolean variables ( 0 or 1$)$ are sufficient to represent the most relevant situations, but whenever needed, multivalued variables can be used.

Based on available data on co-aggregation of FceRI with the inhibitory receptor Fc $\gamma$ RIIB, we abstracted relevant information from the reaction map to define a regulatory graph. Beyond molecular interactions delineated using low-throughput approaches, we have used the proteomic data reported in Bounab et al. (2013), which point to novel SLP76 interactants, some previously reported in T or B cell activation processes, but now specifically identified in mastocytes.

Based on the 45 material components extracted with BiNoM (Figure 5A), we have considered 42 molecular species in the regulatory graph shown in Figure 6. The following step is the assignment of logical rules for each regulatory component in order to specify its target activity level according to the levels of its regulators. In most cases, this is straightforward, but it becomes tricky when many regulators converge onto a single component. Figure 7 illustrates the relationship between regulatory interactions and logical rules on the one hand, and the underlying molecular subnetworks on the other hand. The structure of the regulatory network and the logical rules are iteratively refined based on the comparison between simulation and documented network properties.

Once a regulatory graph and a set of regulatory rules are defined, the user can select a set of initial values for the components and use GINsim to compute a state transition graph, highlighting stable states and cyclic attractors. However, as the number of components considered increases, such simulations become rapidly challenging from a computational point of view. In this respect, the recent development of a rigorous logical model reduction approach and its implementation into GINsim currently allow the simulation and analysis of regulatory networks encompassing hundreds of components (Naldi et al., 2011). The basic idea consists in enabling the user to select a series of components to hide. The software then hides them iteratively one at a time and recomputes the logical rules of their targets. Provided that no regulatory circuit is eliminated in this process (which is forbidden by the algorithm), it has been proven that the most salient dynamical properties are preserved, including all stable states, which typically represent different cellular states.

\section{Coherence of the logical model behavior with published data}

In order to evaluate the coherence of the global behavior of the model with current biological knowledge, we compared its dynamical properties with published data. First, we computed the stable states of the model and compared them with available data. Next, we performed asynchronous simulations for specific initial conditions (input levels, initial states, in the presence of perturbations or not). Inconsistencies were progressively fixed through appropriate modifications of the logical rules and/ or adding or removing an interaction or a model component.

Of particular interest are the sets of states forming attractors, i.e. groups of states from which the system cannot escape, which represent potential asymptotic behaviors. Attractors can be classified 
into two main categories: stable states and cyclic attractors (denoting periodic or homeostatic behavior). From a biological point of view, the asymptotic behavior represents the ultimate cellular outcome induced by an initial configuration.

The three inputs of the model correspond to antigen activity on the receptors (considering three levels: $\mathrm{Ag}=0,1$ or 2), cCbl activity, and PIP2 activity, respectively. $\mathrm{Ag}=1$ corresponds to the aggregation of FceRI, while $A g=2$ denotes co-aggregation of FceRI with FcyRIIB. The second input, PIP2 activity is important for the activation of certain pathways (PIP3, $\mathrm{Ca}^{2+}$ ). Finally, cCbl stands for an ubiquitin-protein ligase targeting Syk and Lyn tyrosine kinases for degradation.

The six outputs of the model and one intermediate component (component $\mathrm{Ca}$, denoting $\mathrm{Ca}^{2+}$ ) are used to define the functional outcome. AP1, Elk1, Akt, NF-kB, NFAT are associated with cytokine release, PLA with the synthesis of lipidic mediators, and $\mathrm{Ca}$ with degranulation.

Table II lists the stable states (ss) obtained for the unperturbed model. For wild type conditions, the model shows that, in the absence of antigen, no matter of the values of the other inputs, signaling is abolished (ss1 and ss2). However, the stable state ss3 correspond to a situation where transient but substantial activation would nevertheless lead to cytokine release, degranulation and lipidic mediator synthesis. Indeed, this state can only be attained when Syk is provided in the initial conditions (cf. Model file available in the model repository on GINsim website, at http://www.ginsim.org).

For medium receptor activation $(\mathrm{Ag}=1)$, we have two possible stable states, ss4 and ss5. In the first case (ss4), the FceRI dependent pathways are activated provided that Lyn, Syk and PIP2 are initially present, while in the second case (ss5), in the absence of Lyn and Syk, no matter the values of the other two inputs, FceRI dependent pathways are not activated.

For high receptor activation $(\mathrm{Ag}=2)$, we obtain three stable states, ss6, ss7 and ss8. The first one (ss6) is very similar to ss5, meaning again that, in the absence of Lyn and Syk, no matter the values of the other two inputs, we have no activation. In the second case (ss7), the presence of Lyn and Syk in the absence of the other inputs can result in the activation of intermediate components, but we have a final down-regulation of NFkB, NFAT, AP1, PLA, and Elk1. The third case (ss8) corresponds to a full pathway activation in the presence of Lyn, Syk and PIP2.

To further assess the behavior of our model in comparison with published data we designed and performed a series of in silico experiments (simulations) combining different initial conditions and virtual perturbations (loss of functions, gain of functions of selected model components). As already mentioned above, for the simulation part, we reduced our model using a specific function of GINsim, resulting in reduced model version encompassing 31 components.

Table III shows the results obtained for simulations corresponding to two different genetic backgrounds.

Analysis of FceRI signaling pathways in Syk-deficient mast cells indicates that Syk is not required for the activation of Lyn. In contrast, FceRI-induced rise in intracellular $\mathrm{Ca}^{2+}$ and activation of the ERK and JNK MAP kinase pathways is completely abrogated in the absence of Syk. Furthermore, phosphorylation of phospholipase $\mathrm{C} \gamma 1$ (PLC $\gamma 1)$ and of the Vav1 exchange factor is also Sykdependent (Simon et al., 2005). In Syk knockout experiments, degranulation and cytokine release are both abolished (Gilfillan et al., 2006).

To check the consistency of our model with these data, we performed an in silico simulation of Syk knockout, with Lyn and PIP2 present and Ag set to level 2 at the initial state. Note that Lyn level needs to be set at its initial state as we lack information about its upstream regulator(s). The results of this simulation are shown in Table III (third column). In this situation, the system reaches a stable state where AP-1, ERK, JNK, Elk-1, NF-kB, NFAT, PKC, PLCG1, Ca2 ${ }^{+}$and Vav are all set to zero, in agreement with the published data. 
In the case of Btk knockout, a decrease in degranulation and cytokine release, as well as a decrease of PLCG1, ERK and JUN levels have been observed (Kawakami et al., 2000; Setoguchi et al., 1998). The simulation of Btk knockout indeed results into a decrease of PLCG1 and ERK (set to zero), in agreement with published data.

Certain mutant phenotypes are not easy to assess because the data are still controversial (e.g. Lyn knockout and its effect on degranulation). Other mutant simulations give self-evident results (e.g. Gab2 knockout results in the blockage of PI3K dependent pathway). Comparing the results for WT and Gab2 knockout mutant, starting from initial conditions where PI3K and Gab2 are set to zero, we observed that their activation is only transient (data not shown).

In the case of Lyn knockout, it has been observed that PI3K activity is increased, while that FcR $\beta$ and FcR $\gamma$ phosphorylation is decreased, and MAP and JUN phosphorylation prolonged (Gilfillan et al., 2006). Our model does not yet account for these results, pointing to gaps in our knowledge regarding Lyn activation and role.

For LAT knockout and knockdown mice, a decrease on degranulation, cytokine release, SLP76 and PLC $\gamma$ phosphorylation, and MAPK activity have been observed, with no change in Syk and Vav phosphorylation (Gilfillan et al., 2006). Our model is partly coherent with experimental data, as the simulation of a LAT knockout mutant points to a decrease in cytokine release (decrease of AP-1, Erk, NFAT, NFkB), in calcium ions and PLC $\gamma$, with no change in Syk and Vav activity.

On the other hand, for LAT2 knockout, an increase of degranulation and cytokine release, and a hyper-phosphorylation of ERK1 and 2, PLC $\gamma$ and LAT have been observed (Gilfillan et al., 2006). Our model does not account for these results, since simulations of LAT2 loss-of-function shows no difference from the WT. This inconsistency can likely be attributed to gaps in our knowledge in the functioning of the inhibitory pathway. As more data will become available, a more refined modeling of this pathway could be established. Regarding SLP76 knockout, a decrease of degranulation, cytokine release, calcium signaling and PLC $\gamma$ phosphorylation have been reported. The corresponding simulation leads to a decrease in cytokine release (decrease of AP-1, JNK, NFAT, $\mathrm{NFkB}$ ), while calcium and PLC $\gamma$ activity are preserved. Here also, our model could be refined to better take into account the different potential sources of calcium ions, once they will be better characterized.

Loss of SHIP expression in vivo has been shown to lead to high Akt activation in bone marrowderived mast cells in response to cytokine stimulation (Liu et al., 1999).

Simulations of SHIP1 knockout mutants indicates that its absence does not suffice to activate Akt. To reach full activation of Akt, our model suggests that Csk must be also inactive, thereby enabling Fyn to phosphorylate and activate Gab2. The simulation of a double SHIP-1 and Csk knock-out indeed results in the activation of Akt.

Regulatory circuits (or feedback loops) have been reported to play crucial roles in the generation of specific dynamical properties, such as multistability or periodic behaviour. Multistationarity is related to the presence of positive circuits, while oscillatory behavior depends on the presence of negative ones (for a review, see Thieffry, 2007). In this respect, GINsim includes an algorithm enabling the identification of all regulatory circuits embedded in a logical model, along with the delineation of functionality conditions, i.e. conditions on the levels of external regulators enabling a circuit to generate the corresponding property.

In the case of our mast cell activation model, the analysis of circuits emphasizes the functionality of two positive circuits, corresponding to Lyn and Syk auto-phosphorylations, and of one negative comprising Raf, MEK, ERK, GRB2-SOS and RAS, suggesting a mechanism underlying the oscillatory behavior observed for medium Ag levels (data not shown). 


\section{Outlook}

In this article, we have reported a systematic effort to model FceRI signaling using all the relevant information available.

The molecular map presented here is the result of the integration of information found in the numerous publications. After taking into account suggestions and corrections from experts, the map has been released on the web. The feedback from the scientific community and the publication of novel results will lead to further updating.

Subsequently, the map can be used as a template in order to visualize experimental data, gaining valuable insights about the specific parts of the signaling cascade that play a major role in response to specific stimuli. Using Cytoscape and BiNoM software, topological and material analyses have been performed to characterize the structure of the underlying network, decompose it into modules and thereby simplify its representation and ease navigation.

The molecular map and its modular representations have in turn been used to build a dynamical model, using a logical formalism. The derivation of a logical model and its calibration (through the specification of the logical rules) lead us to reconsider and update specific parts of the map. Furthermore, model simulations resulted in some inconsistencies (e.g. regarding Lyn knockout), thereby fostering gaps in our knowledge and the need for further model refinements.

This logical modeling approach enabled the recapitulation of several dynamical properties of an extremely complex biological system, such as Fc receptor signaling. Systematic testing of different initial conditions and stimuli could further lead to predictions regarding the outcomes of single or multiple perturbations (e.g. mutations, use of specific enzymatic inhibitors), as well as potential drug-able points.

As further experimental data will be gathered regarding the cascades of Fc receptor signaling, our logical model could serve as a template to design continuous or stochastic models enabling more quantitative predictions. Ultimately, dynamical model analyses should help to understand in more details how the different functional outcomes of mast cell activation (degranulation, synthesis of lipidic mediators, induction of cytokine transcription) are articulated at the level of the underlying molecular network, and to what extend it might be possible to uncouple these functions and delineate means to control them separately or collectively.

\section{Acknowledgements}

This project was supported by the ANR through the MI2 project iSa and by the proteomics ProFI infrastructure, as well as by the French excellence initiatives MemoLife LabEx and PSL* IdEx. 


\section{References}

Alvarez-Errico D, Lessmann E, Rivera J (2009). Adapters in the organization of mast cell signaling. Immunol Rev 232(1): 195-217.

Bérenguier D, Chaouiya C, Monteiro PT, Naldi A, Remy E, Thieffry D, Tichit L (2013). Dynamical modeling and analysis of large cellular regulatory networks. Chaos 23(2): 025114.

Bonnet E, Calzone L, Rovera D, Stoll G, Barillot E, Zinovyev A (2013). BiNoM 2.0, a Cytoscape plugin for accessing and analyzing pathways using standard systems biology formats. BMC Syst Biol 7: 18.

Bounab Y, Hesse AM, Iannascoli B, Grieco L, Couté Y, Niarakis A, Roncagalli R, Lie E, Lam KP, Demangel C, Thieffry D, Garin J, Malissen B, Daëron M (2013). Proteomic analysis of the SH2domain-containing leukocyte protein of $76 \mathrm{kDa}$ (SLP76) interactome. Mol Cell Proteomics 12: $2874-89$.

Calzone L, Gelay A, Zinovyev A, Radvanyi F, Barillot E (2008). A comprehensive modular map of molecular interactions in RB/E2F pathway. Mol Syst Biol 4: 173.

Caron E, Ghosh S, Matsuoka Y, Ashton-Beaucage D, Therrien M, Lemieux S, Kitano H (2010). A comprehensive map of the mTOR signaling network. Mol Syst Biol 6: 453.

Chaouiya C, Naldi A, Thieffry D (2012). Logical modelling of gene regulatory networks with GINsim. Methods Mol Biol 804: 463-79.

Chaouiya C, Berenguier D, Keating SM, Naldi A, van Iersel MP, Rodriguez N, Dräger A, Büchel F, Cokelaer T, Kowal B, Wicks B, Gonçalves E, Dorier J, Page M, Monteiro PT, von Kamp A, Xenarios I, de Jong H, Hucka M, Klamt S, Thieffry D, Le Novère N, Saez-Rodriguez J, Helikar $\mathrm{T}$ (2013). SBML qualitative models: a model representation format and infrastructure to foster interactions between qualitative modelling formalisms and tools. BMC Syst Biol 7: 135.

Daëron M, Malbec O, Latour S, Arock M, Fridman WH, (1995a). Regulation of high-affinity IgE receptor-mediated mast cell activation by murine low-affinity $\mathrm{IgG}$ receptors. J Clin Invest. Feb;95(2):577-85.

Daëron M, Latour S, Malbec O, Espinosa E, Pina P, Pasmans S, Fridman WH, (1995b). The same tyrosine-based inhibition motif, in the intracytoplasmic domain of Fc gamma RIIB, regulates negatively BCR-, TCR-, and FcR-dependent cell activation. Immunity. Nov;3(5):635-46.

Funahashi A, Tanimura N, Morohashi M, Kitano H (2003). CellDesigner: a process diagram editor for gene-regulatory and biochemical networks. BIOSILICO 1: 159-62.

Gilfillan AM, Tkaczyk C (2006). Integrated signalling pathways for mast-cell activation. Nat Rev Immunol 6(3): 218-30.

Gilfillan AM, Beaven MA (2011). Regulation of mast cell responses in health and disease Crit Rev Immunol 31(6): 475-529.

Glass L, Siegelmann HT (2010). Logical and symbolic analysis of robust biological dynamics. Curr Opin Genet Dev 20(6): 644-9.

Goldstein B, Faeder JR, Hlavacek WS, Blinov ML, Redondo A, Wofsy C (2002). Modeling the early signaling events mediated by aggregation of FceRI. Mol Immunol 38(16-18): 1213-9.

Grieco L, Calzone L, Bernard-Pierrot I, Radvanyi F, Kahn-Perlès B, Thieffry D (2013). Integrative modelling of the influence of MAPK network on cancer cell fate decision. PLoS Comput Biol 9: e1003286.

Helikar T, Kochi N, Kowal B, Dimri M, Naramura M, Raja SM, Band V, Band H, Rogers JA (2013). A comprehensive, multi-scale dynamical model of ErbB receptor signal transduction in human mammary epithelial cells. PLoS One 8(4): e61757.

Hucka M, Finney A, Sauro HM, Bolouri H, Doyle JC, Kitano H, Arkin AP, Bornstein BJ, Bray D, Cornish-Bowden A, Cuellar AA, Dronov S, Gilles ED, Ginkel M, Gor V, Goryanin II, Hedley 
WJ, Hodgman TC, Hofmeyr JH, Hunter PJ, Juty NS, Kasberger JL, Kremling A, Kummer U, Le Novère N, Loew LM, Lucio D, Mendes P, Minch E, Mjolsness ED, Nakayama Y, Nelson MR, Nielsen PF, Sakurada T, Schaff JC, Shapiro BE, Shimizu TS, Spence HD, Stelling J, Takahashi K, Tomita M, Wagner J, Wang J (2003). The systems biology markup language (SBML): a medium for representation and exchange of biochemical network models. Bioinformatics 19(4): 524-31

Iwaki S, Spicka J, Tkaczyk C, Jensen BM, Furumoto Y, Charles N, Kovarova M, Rivera J, Horejsi V, Metcalfe DD, Gilfillan AM (2008). Kit- and Fc epsilonRI-induced differential phosphorylation of the transmembrane adaptor molecule NTAL/LAB/LAT2 allows flexibility in its scaffolding function in mast cells. Cell Signal 20(1): 195-205.

Jabril-Cuenod B, Zhang C, Scharenberg AM, Paolini R, Numerof R, Beaven MA, Kinet JP (1996). Syk-dependent phosphorylation of Shc. A potential link between FcepsilonRI and the Ras/mitogen-activated protein kinase signaling pathway through SOS and Grb2. J Biol Chem 271(27): 16268-72.

Joshi-Tope G, Gillespie M, Vastrik I, D'Eustachio P, Schmidt E, de Bono B, Jassal B, Gopinath GR, Wu GR, Matthews L, Lewis S, Birney E, Stein L (2005). Reactome: a knowledgebase of biological pathways. Nucleic Acids Res 33: D428-32.

Kanehisa M, Goto S (2000). KEGG: Kyoto encyclopedia of genes and genomes. Nucleic Acids Res 28: $27-30$

Kawakami Y, Kitaura J, Satterthwaite AB, Kato RM, Asai K, Hartman SE, Maeda-Yamamoto M, Lowell CA, Rawlings DJ, Witte ON, Kawakami T (2000). Redundant and opposing functions of two tyrosine kinases, Btk and Lyn, in mast cell activation. J Immunol 165(3): 1210-9.

Kinet JP (1999). The high-affinity IgE receptor (Fc epsilon RI): from physiology to pathology. Annu Rev Immunol 17: 931-72.

Klipp E, Liebermeister W, Helbig A, Kowald A, Schaber J (2007). Systems biology standards - the community speaks. Nat Biotech 25: 390-1.

Kovárová M, Tolar P, Arudchandran R, Dráberová L, Rivera J,, Dráber P (2001). Structure-function analysis of Lyn kinase association with lipid rafts and initiation of early signaling events after Fcepsilon receptor I aggregation. Mol Cell Biol 21(24): 8318-28.

Kraft S, Kinet JP (2007). New developments in FcepsilonRI regulation, function and inhibition. Nat Rev Immunol 7(5): 365-78.

Krull M, Pistor S, Voss N, Kel A, Reuter I, Kronenberg D, Michael H, Schwarzer K, Potapov A, Choi C, Kel-Margoulis O, Wingender E (2006). TRANSPATH: an information resource for storing and visualizing signaling pathways and their pathological aberrations. Nucleic Acids Res 34: D546-D551.

Kuperstein I, Cohen DP, Pook S, Viara E, Calzone L, Barillot E, Zinovyev A (2013). NaviCell: a web-based environment for navigation, curation and maintenance of large molecular interaction maps. BMC Syst Biol 7(1): 100.

Le Novere N, Finney A, Hucka M, Bhalla US, Campagne F, Collado-Vides J, Crampin EJ, Halstead M, Klipp E, Mendes P, Nielsen P, Sauro H, Shapiro B, Snoep JL, Spence HD, Wanner BL (2005). Minimum information requested in the annotation of biochemical models (MIRIAM). Nat Biotech 23: 1509-15.

Liu Q, Sasaki T, Kozieradzki I, Wakeham A, Itie A, Dumont DJ, Penninger JM (1999). SHIP is a negative regulator of growth factor receptor-mediated $\mathrm{PKB} / \mathrm{Akt}$ activation and myeloid cell survival. Genes Dev 13(7): 786-91.

Malbec O, Fong DC, Turner M, Tybulewicz VL, Cambier JC, Fridman WH, Daëron M (1998). Fc epsilon receptor I-associated lyn-dependent phosphorylation of $\mathrm{Fc}$ gamma receptor IIB during negative regulation of mast cell activation. J Immunol 160(4): 1647-58. 
Mendoza L (2006). A network model for the control of the differentiation process in Th cells. Biosystems 84(2): 101-14.

Nag A, Faeder JR, Goldstein B (2010). Shaping the response: the role of FceRI and Syk expression levels in mast cell signaling. IET Syst Biol 4 (6): 334-47.

Naldi A, Berenguier D, Fauré A, Lopez F, Thieffry D, Chaouiya C (2009). Logical modelling of regulatory networks with GINsim 2.3. Biosystems 97(2): 134-9.

Naldi A, Remy E, Thieffry D, Chaouiya C (2011). Dynamically consistent reduction of logical regulatory graphs. Theor Comput Sci 412(21): 2207-18.

Oda K, Matsuoka Y, Funahashi A, Kitano H (2005). A comprehensive pathway map of epidermal growth factor receptor signaling. Mol Syst Biol 1: 2005.0010.

Saez-Rodriguez J, Mirschel S, Hemenway R, Klamt S, Gilles ED,, Ginkel M (2006). Visual setup of logical models of signaling and regulatory networks with ProMoT. BMC Bioinformatics 7: 506.

Saez-Rodriguez J, Simeoni L, Lindquist JA, Hemenway R, Bommhardt U, Arndt B, Haus UU, Weismantel R, Gilles ED, Klamt S, Schraven B (2007). A logical model provides insights into T cell receptor signaling. PLoS Comput Biol 3(8): e163.

Saitoh S, Arudchandran R, Manetz TS, Zhang W, Sommers CL, Love PE, Rivera J, Samelson LE (2000). LAT is essential for Fc(epsilon)RI-mediated mast cell activation. Immunity 12(5): 52535.

Samaga R, Saez-Rodriguez J, Alexopoulos LG, Sorger PK, Klamt S (2009). The logic of EGFR/ErbB signaling: theoretical properties and analysis of high-throughput data. PLoS Comput Biol 5(8): e1000438.

Sahin O, Fröhlich H, Löbke C, Korf U, Burmester S, Majety M, Mattern J, Schupp I, Chaouiya C, Thieffry D, Poustka A, Wiemann S, Beissbarth T, Arlt D (2009). Modeling ERBB receptorregulated G1/S transition to find novel targets for de novo trastuzumab resistance. BMC Syst Biol 3: 1 .

Setoguchi R, Kinashi T, Sagara H, Hirosawa K, Takatsu K. (1998). Defective degranulation and calcium mobilization of bone-marrow derived mast cells from Xid and Btk-deficient mice. Immunol Lett 64(2-3): 109-18.

Shannon P, Markiel A, Ozier O, Baliga NS, Wang JT, Ramage D, Ideker T (2003). Cytoscape: a software environment for integrated models of biomolecular interaction networks. Genome Res 13(11): 2498-504.

Simon M, Vanes L, Geahlen RL, Tybulewicz VL (2005). Distinct roles for the linker region tyrosines of Syk in FcepsilonRI signaling in primary mast cells. J Biol Chem 280(6): 4510-7.

Thieffry D (2007). Dynamical roles of biological regulatory circuits. Brief Bioinform 8: 220-5.

Tůmová M, Koffer A, Simíček M, Dráberová L, Dráber P (2010). The transmembrane adaptor protein NTAL signals to mast cell cytoskeleton via the small GTPase Rho. Eur J Immunol 40(11): 3235-45.

Young RM, Holowka D, Baird B (2003). A lipid raft environment enhances Lyn kinase activity by protecting the active site tyrosine from dephosphorylation. J Biol Chem 278(23): 20746-52.

Zhu M, Liu Y, Koonpaew S, Granillo O, Zhang W (2004). Positive and negative regulation of FcepsilonRI-mediated signaling by the adaptor protein LAB/NTAL. J Exp Med 200(8): 9911000.

Zinovyev A, Viara E, Calzone L, Barillot E (2008). BiNoM: a Cytoscape plugin for manipulating and analyzing biological networks. Bioinformatics 24(6): 876-7. 
A. Niarakis et al.

Table I. Main entries related to FceRI signaling in public pathway databases

\begin{tabular}{|l|l|l|}
\hline DATABASE and URL & $\begin{array}{l}\text { Pathway entry in the } \\
\text { coressponding database }\end{array}$ & $\begin{array}{l}\text { Components and references (when } \\
\text { specified) }\end{array}$ \\
\hline $\begin{array}{l}\text { KEGG Pathway Database } \\
\text { http://www.genome.jp/kegg/pathway.html }\end{array}$ & map04664 & $\begin{array}{l}33 \text { components } \\
7 \text { references }\end{array}$ \\
\hline $\begin{array}{l}\text { Pathway Interaction Database } \\
\text { http://pid.nci.nih.gov }\end{array}$ & Fcer1pathway2 & 78 components \\
\hline $\begin{array}{l}\text { Biocarta } \\
\text { http://www.biocarta.com }\end{array}$ & $\begin{array}{l}\text { Fc Epsilon Receptor I } \\
\text { Signaling in Mast Cells }\end{array}$ & 32 components \\
\hline $\begin{array}{l}\text { Pathway Maps } \\
\text { http://pathwaymaps.com/maps/ }\end{array}$ & $\begin{array}{l}\text { Immune response_Fc epsilon } \\
\text { RI pathway }\end{array}$ & $\begin{array}{l}55 \text { components } \\
13 \text { references }\end{array}$ \\
\hline
\end{tabular}


Table II. Stable states of the logical model for mast cell activation (wild-type). All stable states of the model are listed, which differ regarding input (Ag, cCbl and PIP2) values, and downstream effects. The * refers to both values 0 and 1 .

\begin{tabular}{|c|c|c|c|c|c|c|c|c|}
\hline Component & ss1 & ss2 & ss3 & ss4 & ss5 & ss6 & ss7 & ss8 \\
\hline Ag (input) & 0 & 0 & 0 & 1 & 1 & 2 & 2 & 2 \\
\hline Akt & $*$ & 0 & 0 & 0 & * & $*$ & 0 & 0 \\
\hline AP1 & $*$ & $*$ & 1 & 1 & $*$ & $*$ & 0 & 1 \\
\hline Bcr & 0 & 0 & 0 & 0 & 0 & 0 & 0 & 0 \\
\hline Btk & 0 & 0 & 1 & 1 & 0 & 0 & 0 & 1 \\
\hline $\mathbf{C a}$ & 0 & 0 & 1 & 1 & 0 & 0 & 1 & 1 \\
\hline CCbl (input) & 0 & 0 & 1 & 1 & 0 & 0 & 1 & 1 \\
\hline Csk & 0 & 0 & 1 & 1 & 0 & 0 & 0 & 1 \\
\hline Elk1 & 0 & 1 & 1 & 1 & 0 & 0 & 1 & 1 \\
\hline ERK & 0 & 0 & 1 & 1 & 0 & 0 & 0 & 1 \\
\hline FceRI-IgE_P & 0 & 0 & 1 & 1 & 0 & 0 & 0 & 1 \\
\hline FcgRIIB_P & 0 & 0 & 0 & 1 & 0 & 0 & 1 & 1 \\
\hline Gab2 & 0 & 0 & 0 & 0 & 0 & 0 & 1 & 1 \\
\hline GRB2-SOS & 0 & 0 & 0 & 0 & 0 & 0 & 0 & 0 \\
\hline JNK & 0 & 0 & 0 & 0 & 0 & 0 & 0 & 0 \\
\hline LAT & 0 & 0 & 1 & 1 & 0 & 0 & 1 & 1 \\
\hline LAT2 & 0 & 0 & 1 & 1 & 0 & 0 & 1 & 1 \\
\hline Lyn & 0 & 0 & 1 & 1 & 0 & 0 & 1 & 1 \\
\hline NFAT & 0 & 1 & 1 & 1 & 0 & 0 & 1 & 1 \\
\hline NFkB & 0 & 0 & 1 & 1 & 0 & 0 & 0 & 1 \\
\hline PIP2 (input) & 0 & 0 & 1 & 1 & 0 & 0 & 0 & 1 \\
\hline PKC & 0 & 0 & 1 & 1 & 0 & 0 & 0 & 1 \\
\hline PLA & 0 & 0 & 1 & 1 & 0 & 0 & 0 & 1 \\
\hline PLCG1 & 0 & 0 & 1 & 1 & 0 & 0 & 1 & 1 \\
\hline Rac1 & 0 & 0 & 1 & 1 & 0 & 0 & 1 & 1 \\
\hline RAS & 0 & 0 & 1 & 1 & 0 & 0 & 0 & 1 \\
\hline RasGAP-Dok1 & 0 & 0 & 0 & 0 & 0 & 0 & 1 & 1 \\
\hline SHIP1 & 0 & 0 & 0 & 0 & 0 & 0 & 1 & 1 \\
\hline SLP76 & 0 & 0 & 1 & 1 & 0 & 0 & 1 & 1 \\
\hline Syk & 0 & 0 & 1 & 1 & 0 & 0 & 1 & 1 \\
\hline Vav & 0 & 0 & 1 & 1 & 0 & 0 & 1 & 1 \\
\hline
\end{tabular}


Table III. Examples of simulations for full receptor activation. Columns 2, 3 and 4 correspond to wildtype, and Syk and Btk knock-outs, respectively. In each case, we start with initial conditions with $\mathrm{Ag}=2$, Lyn=PIP2=1, all other components being set to zero. For both mutants, calcium signaling (hence degranulation), NFkB, NFAT and AP1 activity (hence cytokine release), and PLA activation (hence membrane synthesis) are impaired, although we observe a broader impact of Syk KO on the activity of signaling components.

\begin{tabular}{|l|c|c|c|}
\hline Component & WT & Syk KO & Btk KO \\
\hline Ag (input) & 2 & 2 & 2 \\
\hline Akt & 0 & 0 & 0 \\
\hline AP1 & 1 & 0 & 0 \\
\hline Bcr & 1 & 0 & 1 \\
\hline Btk & 1 & 0 & 0 \\
\hline Ca & 1 & 0 & 0 \\
\hline CCb1 (input) & 0 & 0 & 0 \\
\hline Csk & 1 & 1 & 1 \\
\hline Elk1 & 1 & 0 & 1 \\
\hline ERK & 1 & 0 & 0 \\
\hline FceRI-IgE_P & 1 & 1 & 1 \\
\hline FcgRIIB_P & 1 & 1 & 1 \\
\hline Gab2 & 0 & 0 & 0 \\
\hline GRB2-SOS & 0 & 0 & 0 \\
\hline JNK & 1 & 0 & 1 \\
\hline LAT & 1 & 0 & 1 \\
\hline LAT2 & 1 & 0 & 1 \\
\hline Lyn & 1 & 1 & 1 \\
\hline NFAT & 1 & 0 & 0 \\
\hline NFkB & 1 & 0 & 0 \\
\hline PIP2 (input) & 1 & 1 & 1 \\
\hline PKC & 1 & 0 & 0 \\
\hline PLA & 1 & 0 & 0 \\
\hline PLCG1 & 1 & 0 & 0 \\
\hline Rac1 & 1 & 0 & 1 \\
\hline RAS & 1 & 0 & 0 \\
\hline RasGAP-Dok1 & 1 & 1 & 1 \\
\hline SHIP1 & 1 & 1 & 1 \\
\hline SLP76 & 1 & 0 & 1 \\
\hline Syk & 1 & 0 & 1 \\
\hline Vav & & & 1 \\
\hline
\end{tabular}


Figures and Legends of the Figures

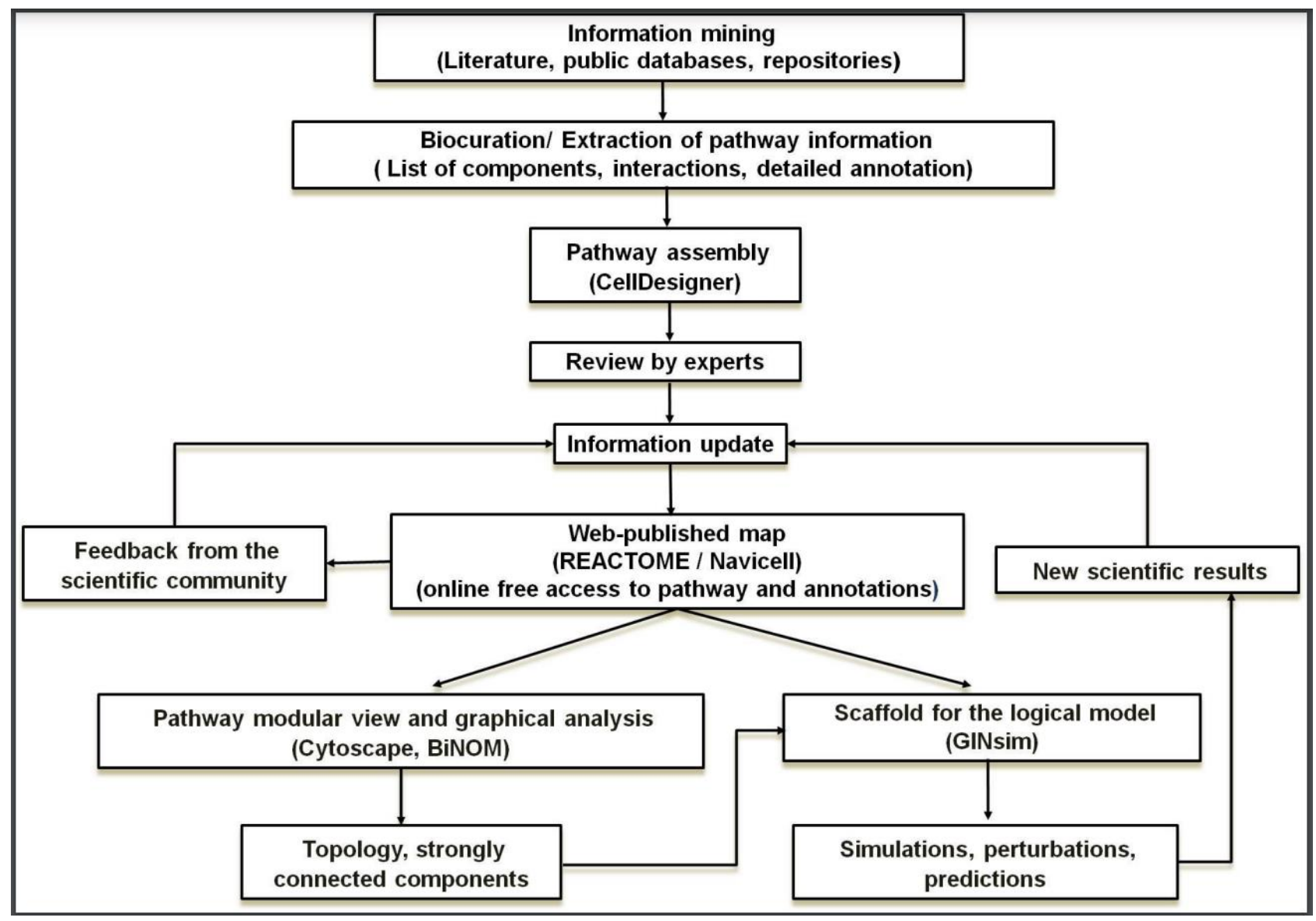

Figure 1. Data integration workflow. The construction of a logical model is a multistep process involving several iterations. First, a map of relevant biological pathways integrating information from literature and public databases is built. Experts then curate this map, leading to the publication of an updated version on the web. Web publication facilitates community feedback and hence further refinements and extensions. Computational biologists can apply graph analysis tools to identify important nodes and pathways, or use it as a scaffold to build dynamical models allowing simulations. Interesting predictions can then be experimentally tested, thereby contributing to the validation and refinement of the map and expanding current knowledge. 


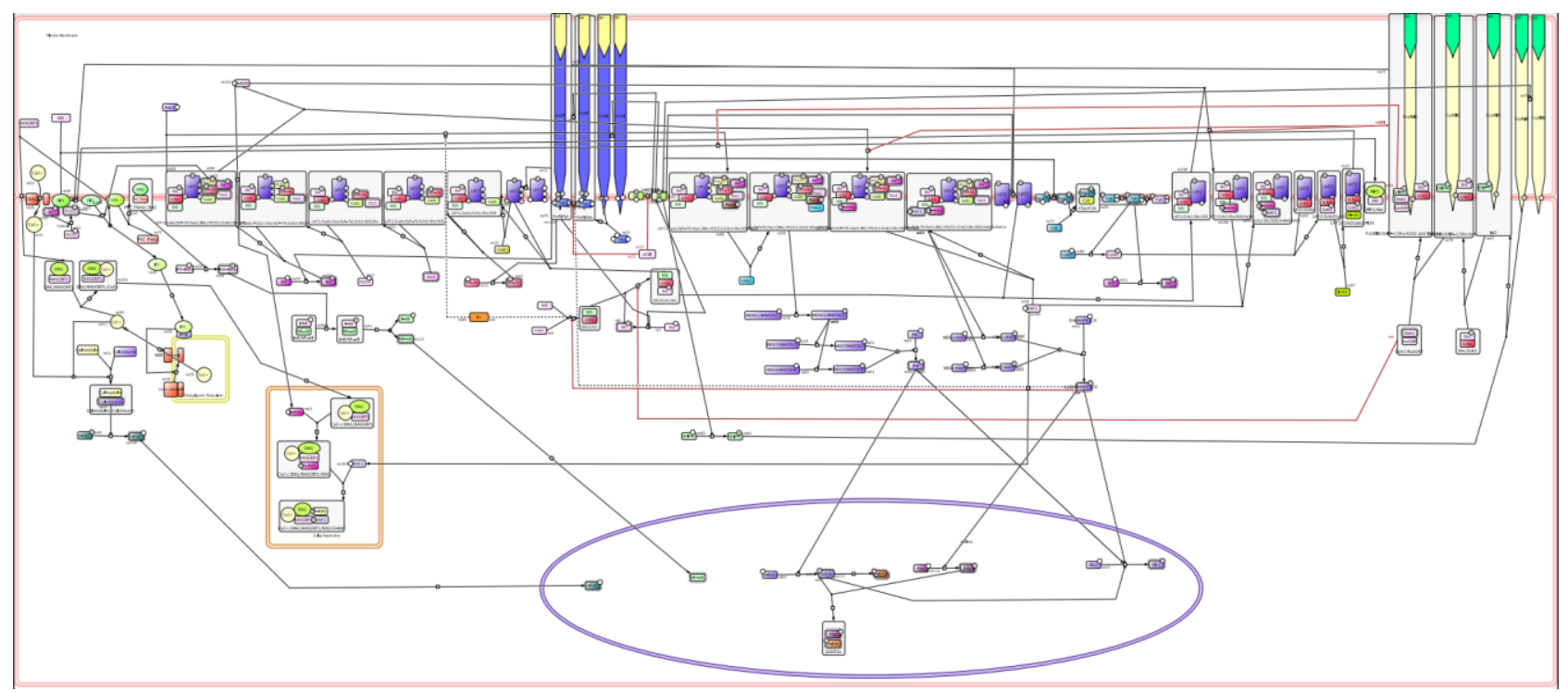

Figure 2. Snapshot of the mast cell activation signaling pathway map created with CellDesigner. Interactions are color coded: black arrows denotes stimulatory reactions; red blunt end arrow denote inhibitions; black round head arrows denote catalysis. Proteins phosphorylation and ubiquitination are depicted by $\mathrm{P}$ and Ub labels, respectively. Dotted contours emphasize activated entities. Plasma membrane, cytoplasm, endoplasmic reticulum, Golgi apparatus, and nucleus compartments are distinguished.

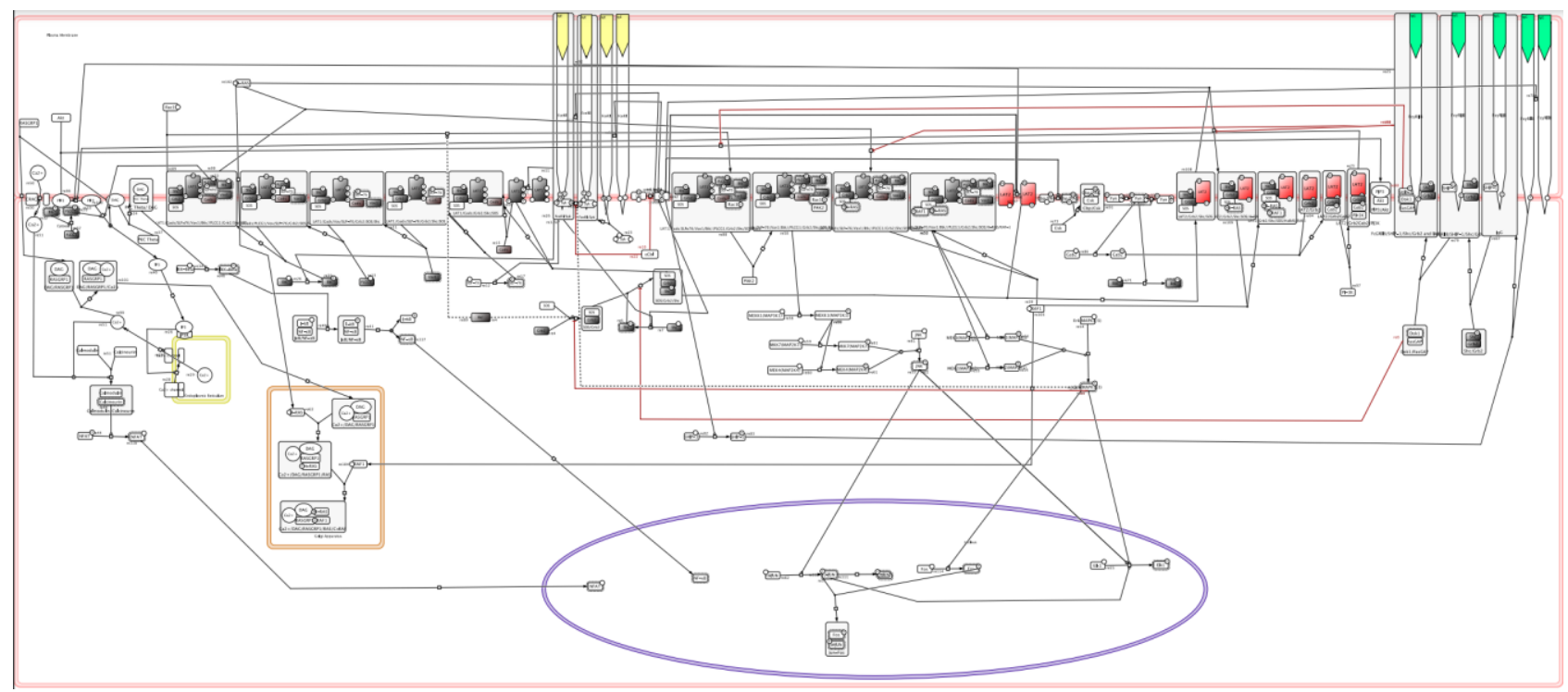

Figure 3. Visualization of proteomic data concerning SLP-76 interactome in activated BMMCs on the mast cell signaling map. A color scale was defined from light grey (minimum detection level) to bright red (for the most enriched) according to the data values. One can see the high enrichment of LAT2 (bright red color) (data from Bounab et al., 2013). 
A. Niarakis et al.

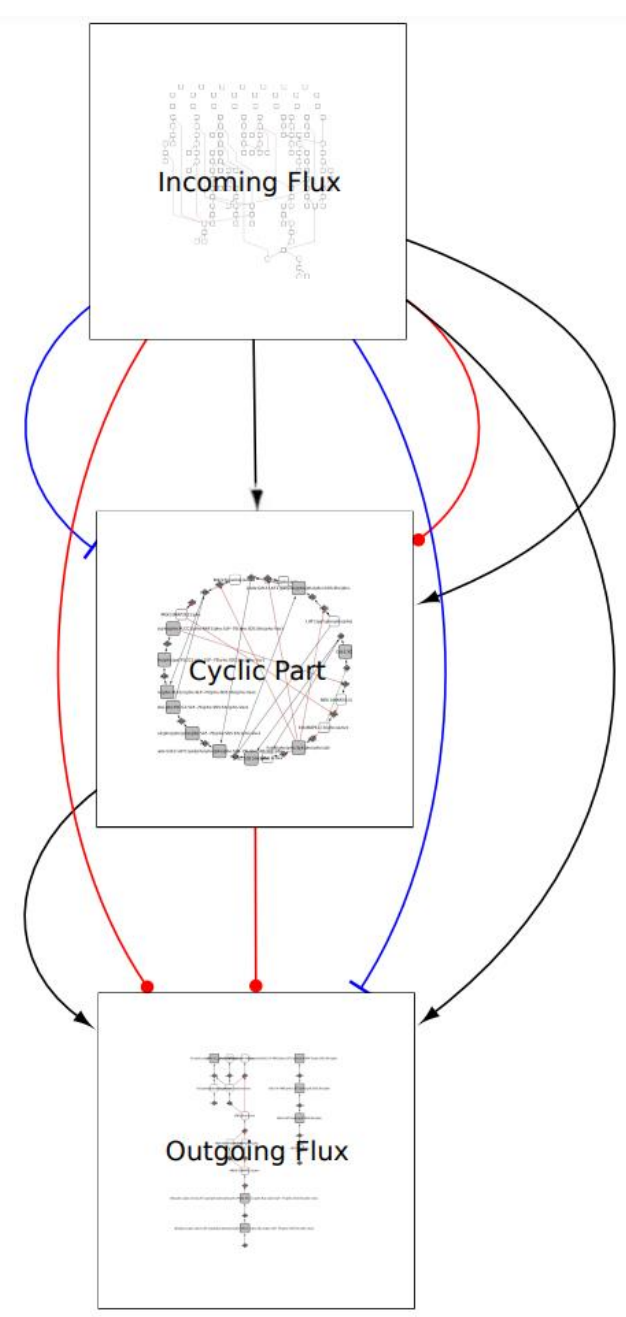

Figure 4. Modular view of the pruned graph of generated from our molecular map using BiNoM. Three modules are obtained corresponding to "incoming flux", "cyclic part", and "outgoing flux", while different kinds of connections between these modules are specified: black arrows: molecular flows; red ball arrows: catalysis, blue blunt arrows: inhibitions. 


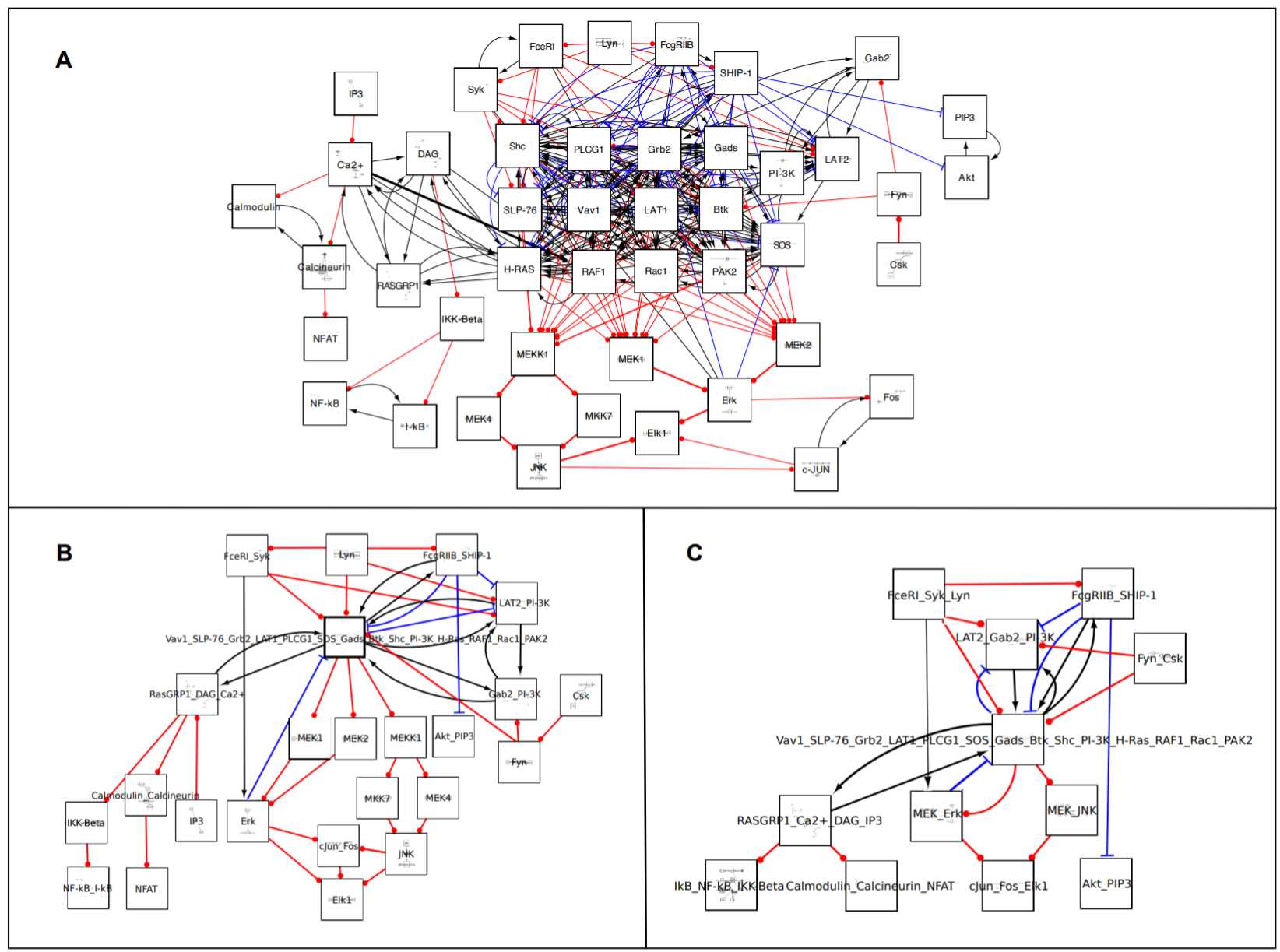

Figure 5. Modular views of the mast cell signaling network (cf. Figure 2) generated with the Cytoscape plugin BiNoM. Modularization according to material components resulted in 45 modules. Clustering of these networks resulted in a reduction of this number. Manual refinement lead in an even more compact representation. Rectangles: modules with nested networks; Red arrows: catalysis; Blue arrows: inhibition; Black arrows: molecular flow. A: 45 modules consisting of material components networks. B: 24 modules deriving from clustering of the material components networks (threshold: $35 \%$ overlapping). C: 12 resulting modules, after manual curation and merging. 


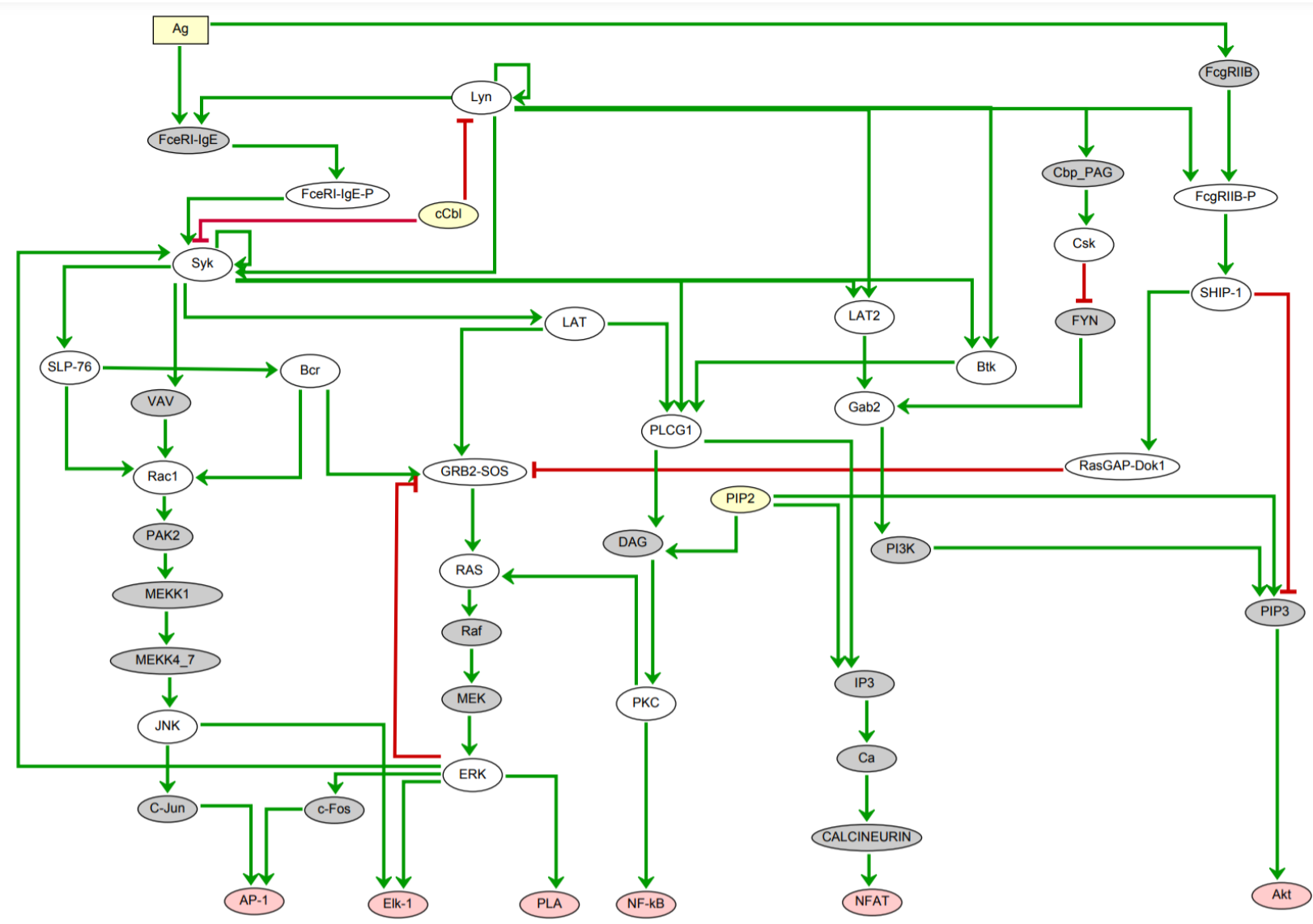

Figure 6. Regulatory graph of the mast cell signaling logical model. The regulatory graph encompasses 47 components. Green/red arcs denote activating/ inhibitory regulations. Ellipsoid nodes represent Boolean variables, while rectangular nodes represent multivariate variables. Inputs and output nodes are emphasized in yellow and pink, respectively. Nodes hidden in the reduced version used for simulations are colored in grey.

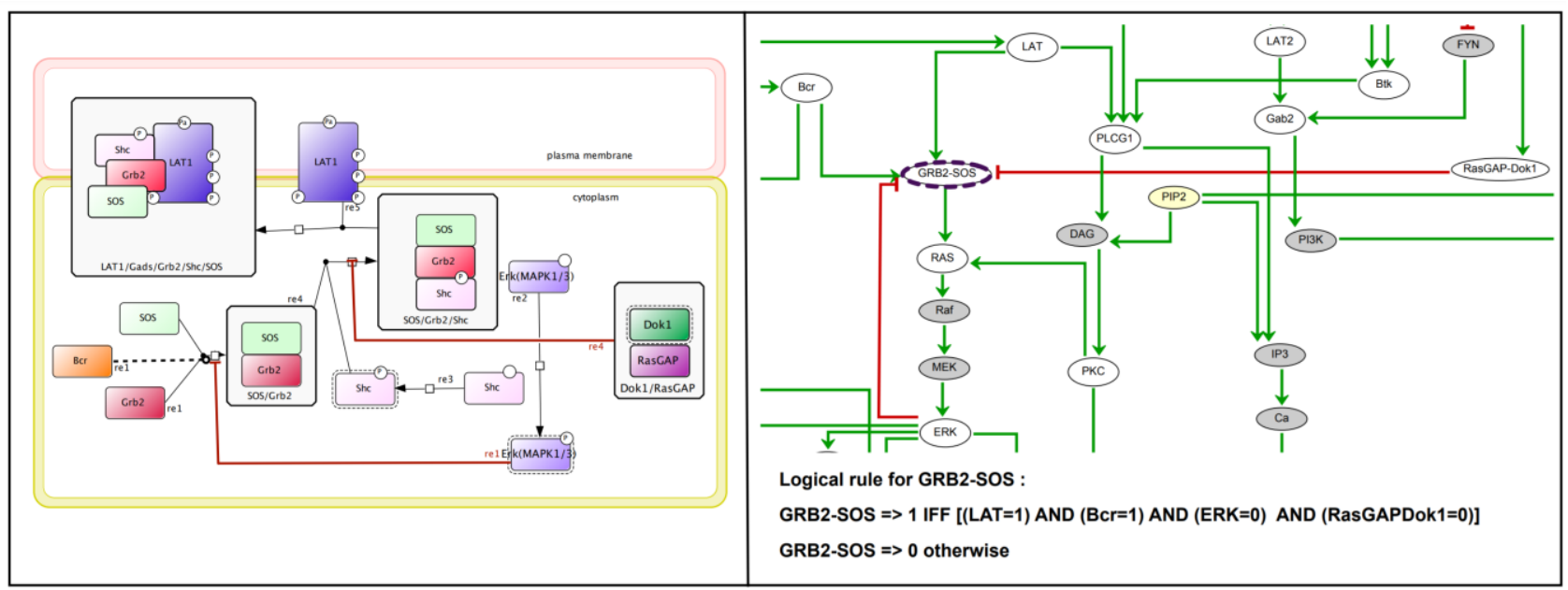

Figure 7. From CellDesigner molecular map to GINsim logical model. A. Zoom in a section of the CellDesigner map. B. Translation of molecular interactions into regulatory interactions into GINsim and delineation of the logical rule for GRB-SOS, whose activity depends on the presence of RasGAP-Dok1, Bcr, LAT and ERK. 